it is stated that information has been received that treasure in gold and precious stones "worth millions" has been discovered in a sealed tomb in the course of excavation, under the direction of Don Alfonso Caso, at Monte Alban, near Oaxaca. The bodies of ten Mixtec caciques were found buried under a heap of cups, urns, vases, and jars of jade, onyx, and crystal, together with personal ornaments and utensils of gold richly inlaid with turquoise. The skulls of the chieftains were encrusted with turquoise, and with them was a finely wrought mask of gold. The disorder of the funerary offerings suggests haste ; and this might have been due to the fact that the interment lies in the country of the Zapotec, with whom the Mixtec, notwithstanding their probable affinity, were frequently at war.

THE richness of the funerary offerings found at Monte Alban is fully in accord with the account given by Balboa, an early writer on the inhabitants of Mexico, of an interment in a cave-the usual type of burial chamber among the Mixtec-situated at Chalcotonga, supposed to be the gate of Paradise, in which the dead were laid out in rich garments and a number of small idols of gold, stone, and wood were placed in niches in the walls of the cave. Primary interments such as the recent discovery are supposed to have been confined to persons of high rank, the lower orders being placed in the ground for a time and their bones then collected and placed in a vase for deposit in a cave. It is suggested that the date of the burial is the fifteenth or early sixteenth century. Notwithstanding the scanty details, it is evident that this is the most imposing discovery of relics of the pre-Columbian culture of Mexico yet made. Its interest is considerably enhanced by the fact that so little relating to the Mixtec, who may in part have been of pre-Aztec strain, had been discovered previously.

\section{Electrical Measuring Instruments}

A SPECIAI exhibition of electrical measuring instruments opens at the Science Museum, South Kensington, on Feb. 13, and will remain on view until the middle of May. The exhibition illustrates the evolution of electrical measuring instruments, from the discovery of the fundamental principles on which they are based, up to the present day, and is substantially the same as the exhibition arranged by the British Electrical and Allied Manufacturers' Association and shown on the occasion of the Faraday Centenary Exhibition at the Albert Hall in September last. With the view of interesting the non-technical public, a series of simple demonstration experiments has been arranged to illustrate the various fundamental principles and their application to electrical measurement. Demonstrations will be given daily, the apparatus in some cases being a replica of that used by the original discoverer of the principle. The exhibition, which comprises about 250 exhibits, includes many original instruments, such as Kelvin's reflecting galvanometer, a resistance coil used by Wheatstone, Joule's current balance, and the coil with which Maxwell determined the ohm. Among the interesting replicas are those of Orsted's Compass, with which the magnetic effect of an electric current was first demonstrated, Ampère's electrodynamic apparatus, the apparatus with which Ohm discovered 'Ohm's Law', and Sturgeon's electromagnetic engine, which was the first machine to ernbody a commutator.

\section{Weights and Linear Measures}

IN addition, a small exhibition of weighing and linear measuring instruments will be on view in the Main Entrance Hall of the Science Museum from February until May. The exhibition illustrates briefly, by objects and photographic transparencies, progress in metrology since early times. In the very limited space available, only one form of balance has been selected for illustration--the precision or equal-armed balance; similarly, only standard scales and micrometer development have been shown in the linear section. The exhibits include, however, the principal British Exchequer standard weights and linear measures from the time of Henry VII. (1485), excepting, of course, the current national standards. This collection, hitherto in charge of the Standards Department of the Board of Trade, has now been transferred to the Science Museum.

\section{World's Commercial Electricity Supply}

Thanks to the activities of the World Power Conference, data in connexion with the supply of electricity throughout the world are now available. It appears that in 1930 the total capacity of the electric generators used was 114 million kilowatts and that the electric units (kw.h.) generated were 304,000 million. The electricity supply industry represents the largest public utility service in the world, and the capital invested in it almost equals the capital invested in railways. If we take as our unit a 1000 million $\mathrm{kw} . \mathrm{h}$., the total output of electricity in North America was 139, of which the United States generated 121, about two-fifths of the total world output. Germany comes next with an output of 29.4, Canada with 17.8, Great Britain with 17.2, Japan with $16 \cdot 3$, France with $15 \cdot 9$, and Italy with 10.8. Owing to the world-wide industrial depression, there is a distinct slowing down of the rate of development during this period as compared with the preceding year. This is mainly due to slackness in the industralised countries of western Europe and North America. Statistics in connexion with the capacity of the dynamos installed raise the question of whether the generating equipment throughout the world has outrun the demands made on it. It is a little difficult to answer this question, but we think that when industry revives there will be an immediate demand for more electrical machines.

\section{Northumbrian Coals}

The Fuel Research Board has just issued Paper No. 21 of the Physical and Chemical Survey of the National Coal Resources, being a report on the Yard Seam of Northumberland. The report is a very full one, and appears to be very carefully done. There is only one point to which attention may be directed. In places there is a narrow band of dirty coal at the top of the seam known locally as 'top brat', which the report states is "sometimes known as " roof coal" 